\title{
Virtual First Responders: the Role of Direct-to-Consumer Telemedicine in Caring for People Impacted by Natural Disasters
}

\author{
Lori Uscher-Pines, $\mathrm{PhD}, \mathrm{MSc}{ }^{7}$, Shira Fischer, $\mathrm{MD}, \mathrm{PhD}^{7}$, lan Tong, $\mathrm{MD}^{2}$, Ateev Mehrotra, $\mathrm{MD}, \mathrm{MPH}^{3}$, \\ Rosalie Malsberger, $\mathrm{MPH}^{7}$, and Kristin Ray, $M D, M S^{4}$
}

${ }^{1}$ RAND Corporation, Arlington, VA, USA; ${ }^{2}$ Doctor on Demand, San Francisco, USA; ${ }^{3}$ Harvard Medical School, Boston, MA, USA; ${ }^{4}$ University of Pittsburgh, Pittsburgh, PA, USA. KEY WORDS: telemedicine; telehealth; disaster response; hurricane;
direct-to-consumer.

J Gen Intern Med 33(8):1242-4

DOI: $10.1007 / \mathrm{s} 11606-018-4440-8$

(C) Society of General Internal Medicine 2018
We compared visits for hurricane victims versus other visits across the nation during the same time period. We categorized the reason for the visit using ICD-10 diagnostic categories. ${ }^{3}$ RAND's IRB determined the study was exempt.

\section{RESULTS}

$\mathrm{D}$ irect-to-consumer (DTC) telemedicine offers patients immediate access to remote physicians via personal devices. These services were originally designed for patients seeking care for minor acute illnesses. In disasters, however, DTC telemedicine may facilitate care that would otherwise be inaccessible due to displacement, unpassable roads, emergency closures, or increased demand for healthcare services. ${ }^{1}$ For the first time during the 2017 hurricane season, several DTC telemedicine companies including Doctor on Demand, MDLIVE, Teladoc, American Well, and LiveHealth Online offered free visits to hurricane victims. ${ }^{2}$ To understand the role that DTC telemedicine may play in disaster response and recovery, we describe services provided by one DTC telemedicine company during Hurricanes Harvey and Irma.

\section{METHODS}

We analyzed administrative data from Doctor on Demand in the 30 days following Hurricanes Harvey and Irma (AugustSeptember 2017). For these hurricanes, Doctor on Demand offered free two-way video visits to self-identified victims through the use of a hurricane-specific code that was advertised in affected areas via local and national news and social media. Victims needing care were instructed to visit Doctor on Demand's mobile app or website to self-identify and request an immediate physician consult. Physicians could diagnose, prescribe, and refer patients to other sites for care (e.g., referral to emergency department for a potentially life-threatening condition). Physicians documented the visit, recording one diagnosis code for each visit within the company's electronic medical record. Temporary state regulatory changes allowed out-of-state physicians to provide care during hurricane response.

Published online April 24, 2018
There were 2057 telemedicine visits provided to Harvey ( $n=$ 1414, 69.0\%) and Irma victims $(n=644,31.3 \%)$. In 1297 $(63 \%)$ of these visits, the patients served were first-time users of the telemedicine service. Visit volume peaked between days 3 and 6 after hurricane landfall (Fig. 1). Among participating patients, 1514 (73.6\%) were female, 296 (14.4\%) were age < 17 , and $39(1.9 \%)$ were age $\geq 65$.

Top diagnoses among hurricane victims in the first 7 days and 8-30 days following landfall of Harvey and Irma were similar. Diagnoses for hurricane victims differed slightly from top diagnoses nationally during the same period (Table 1). Acute respiratory illnesses (ARI) (31.3\%) and skin problems (8.3\%) were two of the most common diagnosis categories among hurricane victims in the first week, similar to national data. However, in the first week post-hurricane, visits for chronic conditions (7.2\% among hurricane victims vs. 5.7\% nationally); advice, counseling, and refills (5.7 vs. $3.3 \%$ ), and back and joint concerns, including injuries (6.1 vs. 3.4\%), were more common among hurricane victims. Mental health concerns were less common (5.9 vs. 11.7\%). Physicians located outside of the affected states responded to 1293 (52.6\%) of visits. In 123 (6\%) visits, telemedicine physicians recommended patients seek in-person care (e.g., at an urgent care center, emergency department, or primary care provider).

\section{DISCUSSION}

Beyond establishing the feasibility of this telemedicine service, our results provide context on the clinical needs that prompt disaster victims to seek care via DTC telemedicine. Using telemedicine in disaster response is not new; ${ }^{4,5}$ nonetheless, providing care via a DTC model has only become viable in the past several years because of the widespread growth of smartphone ownership in the U.S.A. and the 


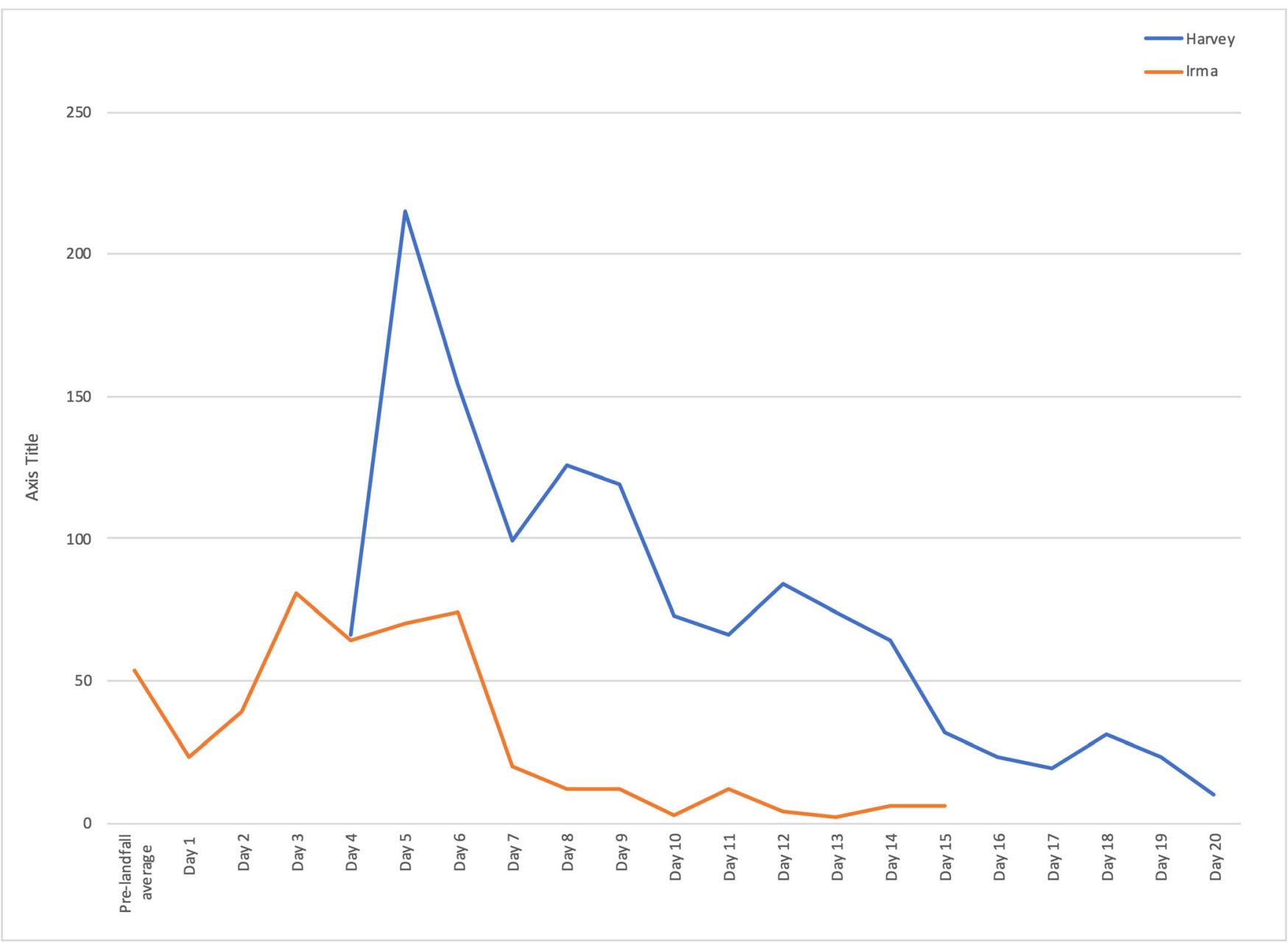

Fig. 1 Timing of visits with self-identified hurricane Harvey and Irma victims. Day 1 is defined as landfall in the U.S.A.; pre-landfall presents the average number of visits in any given day in the pre-landfall period (maximum of 3 days) among users of the hurricane coupon code; data for hurricane Harvey were not available until day 4 after landfall due to a delay in implementing the hurricane coupon code.

corresponding proliferation of DTC telemedicine services which employ thousands of U.S. physicians. ${ }^{6}$

Interestingly, the most common conditions managed during these hurricanes were similar to what is addressed in nondisaster contexts. While there was higher demand for care for chronic illness, overall, our data suggest that DTC telemedicine focuses on the routine needs of new telemedicine users and less on new issues precipitated by the disaster.

One key advantage of telemedicine in disaster response is that out-of-state providers can be tapped to expand the response workforce quickly and cost-effectively. However, the ability of telemedicine to respond does require that certain infrastructures remain in place such as Wi-Fi or cellular service.

This analysis is limited to one telemedicine company. Furthermore, we lacked data on utilization in the first 3 days following landfall of Harvey and on outcomes associated with telemedicine visits. However, our analysis illustrates the emerging role of DTC telemedicine in disaster response.

Acknowledgements: We would like to thank Matt Hurn at Doctor on Demand for providing data to the study team to support the analysis.
Corresponding Author: Lori Uscher-Pines, PhD, MSc; RAND Corporation, Arlington, VA, USA (e-mail: luscherp@rand.org).

Funding This research was supported by RAND Corporation and the National Institutes of Health (K23HD088642, Dr. Ray).

\section{Compliance with ethical standards:}

Conflict of interest: RAND, University of Pittsburgh, and Harvard authors have no conflicts of interest to disclose. This article was coauthored by a physician at Doctor on Demand, the telemedicine company that provided charity care. Doctor on Demand provided data for this article and critically reviewed its content.

\section{REFERENCES}

1. Uscher-Pines L, Fischer S, Chari R. The Promise of Direct-to-Consumer Telehealth for Disaster Response and Recovery. Prehospital and disaster medicine 2016;31(4):454-456.

2. Lagasse $\mathbf{J}$. Doctor on Demand, MDLIVE offer free video visits to victims of Hurricane Harvey. 2017; http://www.mobihealthnews.com/content/doctor-demand-mdlive-offer-free-video-visits-victims-hurricane-harvey. Accessed 2-28-18.

3. Uscher-Pines L, Mehtrotra A. Analysis Of Teladoc Use Seems To Indicate Expanded Access To Care For Patients Without Prior Connection To A Provider. Health Affairs 2014;33(2):258-264. 
Table 1 Leading Diagnosis Categories: Hurricanes Harvey and Irma Victims vs. National

\begin{tabular}{|c|c|c|}
\hline $\begin{array}{l}\text { Top Diagnostic Categories } \\
\text { Nationally in August and } \\
\text { September } 2017(\%)^{* * \dagger}\end{array}$ & $\begin{array}{l}\text { Top Diagnostic Categories for } \\
\text { Harvey and Irma, Days 1-7* } \\
\text { n }(\%)^{* *}\end{array}$ & $\begin{array}{l}\text { Top Diagnostic Categories for } \\
\text { Harvey and Irma, Days 8-30 } \\
\text { n }(\%)^{* *}\end{array}$ \\
\hline $\begin{array}{l}\text { Acute Respiratory illnesses } \\
(31.5 \%)\end{array}$ & $\begin{array}{l}\text { Acute Respiratory illnesses, } 283 \\
(31.3 \%)\end{array}$ & $\begin{array}{l}\text { Acute Respiratory illnesses, } 302 \\
(32.3 \%)\end{array}$ \\
\hline $\begin{array}{l}\text { Mental Health } \\
(11.7 \%)\end{array}$ & Skin Problems, $75(8.3 \%)$ & Skin Problems, 114 (12.2\%) \\
\hline $\begin{array}{l}\text { Skin Problems } \\
(11.2 \%)\end{array}$ & Chronic Illness, 65 (7.2\%) & Chronic Illness, 67 (7.2\%) \\
\hline $\begin{array}{l}\text { UTI and Urinary Symptoms } \\
(9.4 \%)\end{array}$ & Back and Joint, $55(6.1 \%)$ & $\begin{array}{l}\text { UTI and Urinary Symptoms, } 52 \\
(5.6 \%)\end{array}$ \\
\hline $\begin{array}{l}\text { Chronic Illness } \\
(5.7 \%)\end{array}$ & Mental Health, 53 (5.9\%) & Back and Joint, 44 (4.7\%) \\
\hline $\begin{array}{l}\text { Eye Problems } \\
(4.8 \%)\end{array}$ & $\begin{array}{l}\text { General advice / counseling / refills, } \\
52(5.7 \%)\end{array}$ & Allergies, $43(4.6 \%)$ \\
\hline $\begin{array}{l}\text { Abdominal Pain, Vomiting, } \\
\text { and Diarrhea } \\
(3.4 \%)\end{array}$ & $\begin{array}{l}\text { UTI and Urinary Symptoms, } 47 \\
(5.2 \%)\end{array}$ & $\begin{array}{l}\text { Abdominal Pain, Vomiting, and } \\
\text { Diarrhea, } 39(4.2 \%)\end{array}$ \\
\hline $\begin{array}{l}\text { Allergies } \\
(3.4 \%)\end{array}$ & $\begin{array}{l}\text { Internal and External ear Infections, } \\
33(3.6 \%)\end{array}$ & $\begin{array}{l}\text { General advice / counseling / refills, } \\
36(3.8 \%)\end{array}$ \\
\hline $\begin{array}{l}\text { Back and Joint } \\
(3.4 \%)\end{array}$ & Vaginitis, $30(3.3 \%)$ & Eye Problems, 33 (3.5\%) \\
\hline $\begin{array}{l}\text { General Advice / Counseling / } \\
\text { Refills } \\
(3.3 \%)\end{array}$ & $\begin{array}{l}\text { Abdominal Pain, Vomiting, and } \\
\text { Diarrhea, } 24(2.7 \%)\end{array}$ & Mental Health, 30 (3.2\%) \\
\hline
\end{tabular}

* Covers days 1-7 for Irma but only days 4-7 for Harvey due to implementation delay;

**Columns do not add to $100 \%$ because miscellaneous diagnostic categories beyond the top ten are not listed

†N's not included because this data is proprietary

4. Doarn CR, Latifi R, Poropatich RK, et al. Development and validation of telemedicine for disaster response: the north atlantic treaty organization multinational system. Telemedicine and e-health. 2018.

5. Augusterfer EF, Mollica RF, Lavelle J. A review of telemental health in international and post-disaster settings. International review of psychiatry (Abingdon, England) 2015;27(6):540-546
6. Pew Research Center. The smartphone difference. 2015; http://www. pewinternet.org/2015/04/01/us-smartphone-use-in-2015. Accessed 228-18. 